\title{
RHEUMATOID ARTHRITIS WITH LUNG LESIONS
}

\author{
BY \\ T. M. L. PRICE AND M. O. SKELTON \\ From Lewisham Hospital, London, and Lewisham Group Laboratory
}

(RECEIVED FOR PUBLICATION JANUARY 7, 1956)

Ellman and Ball (1948) first adequately described lung lesions in rheumatoid arthritis, regarding them as part of the disease process and as affording further evidence of the tendency of this malady to produce lesions elsewhere than in the joints. Of their three cases, which clinically presented typical rheumatoid arthritis associated with signs of pulmonary disease, two came to post-mortem examination. Histologically the lungs showed patchy fibrosing pneumonitis and alveolar fibrosis which were believed by these authors to indicate rheumatoid damage to the lung parenchyma. Since then other cases have been described, most of them, however, without necropsy confirmation, although Christie (1954) described three cases with careful necropsy studies but without any full description of the radiological changes. More recently, Rubin (1955) described four similar cases, in three of which lung biopsy showed an appearance of fibrosing pneumonitis.

We record here a further case of rheumatoid arthritis with severe lung disease and striking radiological changes in a patient in whom the diagnosis of "rheumatoid lung" was made during life and in whose case necropsy was performed.

\section{CASE RePort}

A woman, aged 58, employed as a cleaner, first came to hospital in March, 1954, complaining of pain and swelling in the small joints of her hands and her right shoulder and both knees for six weeks. She had been well until about a year previously, since when she had noticed slight malaise and a cough, which had increased to a noticeable extent about two months before her first attendance; from this time she had also noticed increasing breathlessness on exertion.

On examination she looked pale, ill, and rather breathless. There was characteristic rheumatoid involvement of the knees and small joints of the hands, particularly the proximal interphalangeal joints of the fingers. Profuse crepitations were heard all over both lung fields. Her blood pressure was $160 / 100 \mathrm{~mm}$. Hg.
INVESTIGATIONS.-Blood count on admission : haemoglobin $85 \%$, leucocytes 10,000 per c.mm. $(78 \%$ polymorphs, $1 \%$ eosinophils, $17 \%$ lymphocytes, $4 \%$ monocytes). The white blood cells were counted on eight subsequent occasions ; the total count was never below 5,500 per c.mm., and on four of them was above 10,500. Lupus erythematosus (L.E.) cells were looked for in the buffy coat once in March, 1954, and were not found. Erythrocyte sedimentation rate (E.S.R.) varied between 7 and $35 \mathrm{~mm}$. in one hour (Wintrobe). Radiographs of the hands showed fusiform soft tissue swellings around the proximal interphalangeal joints and an apparent loss of neighbouring bone density, compatible with rheumatoid arthritis; there were also early osteoarthritic changes in the small joints of the hands. The chest radiograph (Fig. 1) showed widespread mottling in both lung fields. No tubercle bacilli were found on repeated examination of the sputum. The Mantoux test was positive to $100 \mathrm{~T} . \mathrm{U}$. The serum contained $7.32 \mathrm{~g}$. of protein per $100 \mathrm{ml}$., of which albumin was $4.32 \mathrm{~g}$. and globulin $3.00 \mathrm{~g}$. The Wassermann reaction was doubtful, and the Kahn V.D.R.L. flocculation tests negative. An electrocardiogram in June, 1954, showed evidence of right ventricular hypertrophy.

At first pyrexia persisted, up to $100^{\circ} \mathrm{F}$., and both the pain and swelling of the joints and the cough and breathlessness became worse. Rest in bed and full doses of aspirin were of no value.

On June 19 she was given $25 \mathrm{mg}$. of corticotrophin (A.C.T.H.) by intravenous drip, and this was repeated the next day, followed by injections of $25 \mathrm{mg}$. of A.C.T.H. gel daily for 10 days. Joint pain and swelling were much diminished, but attempts to reduce the dosage of A.C.T.H. were followed by immediate exacerbation of these symptoms. On July 21 she was given cortisone, $25 \mathrm{mg}$. thrice daily by mouth, with satisfactory relief of joint symptoms. At no time did either A.C.T.H. or cortisone in any way affect the pulmonary symptoms, which became steadily worse. By December she had developed oedema of the legs. Cortisone was reduced to $50 \mathrm{mg}$. daily in November and was stopped when oedema was first noted. Subsequently the joint pains increased in severity and the oedema subsided.

She was admitted to hospital on January 15, 1955, with extreme dyspnoea, slight oedema of the legs, and 


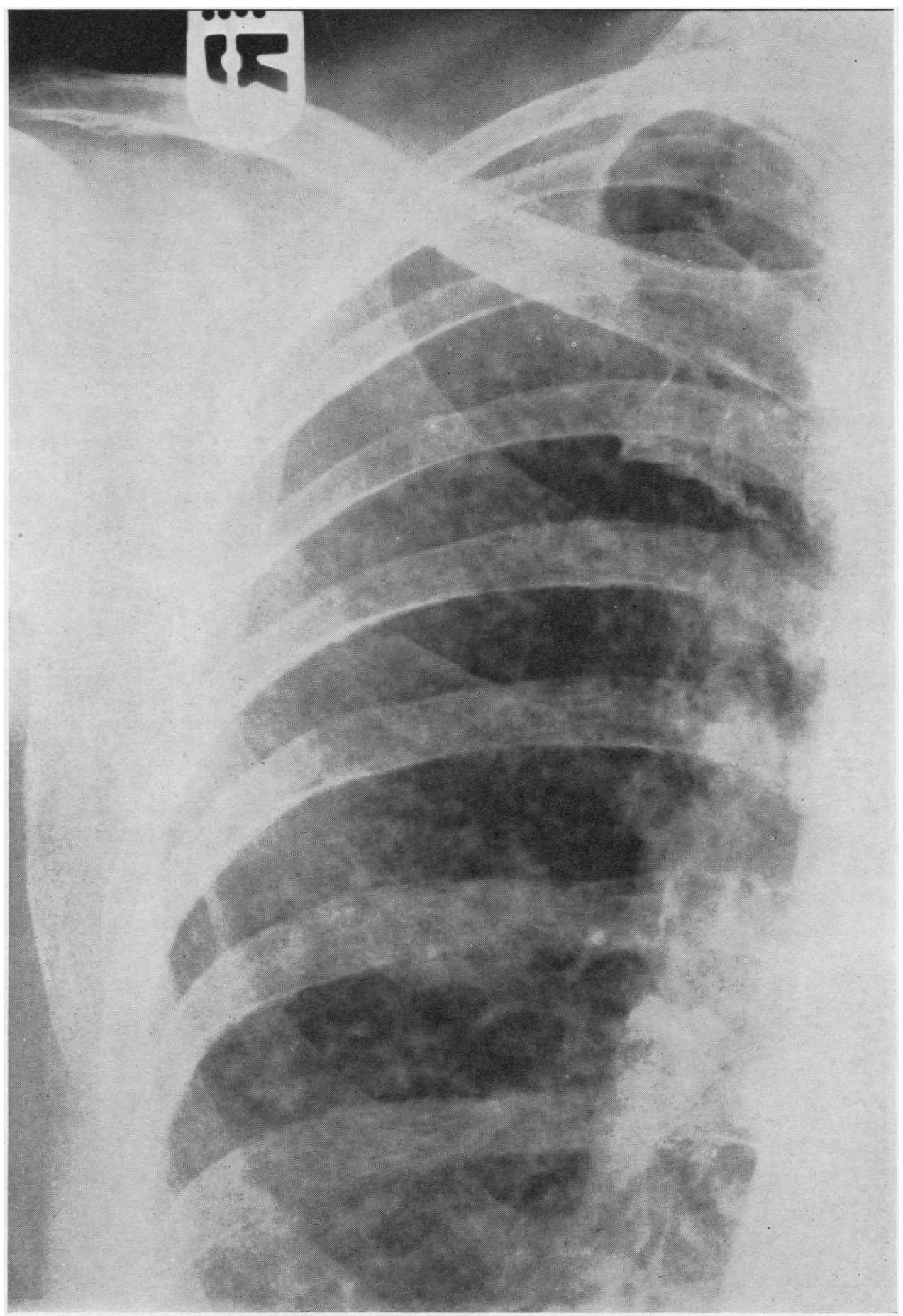

FIG. 1.-Radiograph of upper two-thirds of the right lung, showing diffuse mottling-of both lung fields. 
considerably raised jugular venous pressure. A diagnosis of right-sided heart failure was made, and, though the oedema disappeared with treatment, her general condition deteriorated and she died on February 24.

\section{NECROPSY}

Necropsy was performed five hours after death.

External Appearance.-The body was that of a poorly nourished middle-aged woman $160 \mathrm{~cm}$. in length, showing no oedema, ascites, or jaundice. No clubbing of the fingers; there was a moderate degree of thickening of the metacarpo-phalangeal joints and knee-joints of rheumatoid type.

The abdominal cavity contained a trace of free fluid. There were a few old adhesions between the lateral surface of the spleen and the parietal peritoneum.

The left pleura contained about $100 \mathrm{ml}$. of slightly blood-stained fluid. There were many band-like adhesions of varying age, between the lateral aspect of the lower lobe of the lung and the parietes.

The right pleura contained about $100 \mathrm{ml}$. of bloodstained fluid with a few fibrin clots. Adhesions, mostly recent, were present over the posterior aspect of the lung.

The pericardium contained about $30 \mathrm{ml}$. of clear fluid, with no adhesions.

The heart weighed $368 \mathrm{~g}$. and showed moderate right ventricular hypertrophy; the tricuspid, pulmonary, mitral, and aortic valves, and the myocardium were normal.

The lungs were moderately emphysematous with old interlobar adhesions. The right weighed $464 \mathrm{~g}$. and the left $370 \mathrm{~g}$. The posterior and lateral aspects, particularly of the lower lobes, showed a few old tags of torn adhesions and were covered by a fibrinous exudate in places. Some small haemorrhages were present beneath the pleural surfaces. The cut surface was the normal pinkish grey colour, there was no gross fibrosis, the lung tissue felt slightly drier than usual, and there were some small irregularly shaped reddish purple patches in the lung parenchyma particularly at the bases. No large fibrous nodules were present either in the lung or in the pleura. A few minute beads of pus could be expressed from some of the apical and basal bronchi.

The liver weighed $1,232 \mathrm{~g}$. and was macroscopically normal.

The spleen weighed $120 \mathrm{~g}$., and showed an old perisplenitis but no lesions on gross section.

The oesophagus showed a small diverticulum at the level of the bifurcation of the trachea.

The stomach contained a chronic peptic ulcer, $4 \times 2.5 \mathrm{~cm}$., on the lesser curvature, eroding the pancreas.

The adrenals showed a uniformly thin cortex, between 1 and $2 \mathrm{~mm}$. in thickness.

The kidneys, ureters, bladder, uterus and adnexae, small and large intestines, gall-bladder and bile ducts. thyroid and pituitary glands, cranial cavity and brain showed no naked-eye changes.

\section{Histology}

LUNG.-The pleura was partly covered by an adherent unorganized deposit of fibrin, and showed slight nodular fibrous thickening. The subpleural alveolar septa showed thickening as they blended with the periphery of these nodules (Fig. 2). To the naked eye, sections of the lung showed tiny scattered nodules (Fig. 3) which, microscopically, proved to consist of a bronchiole, with attendant vessels, surrounded by collections of plasma cells and lymphocytes. These complexes were of different sizes, the larger and more active being densely infiltrated by plasma cells and lymphocytes (Fig. 4), and others showing considerable fibrosis (Fig. 5). The nodules were not encapsulated, the fibrous tissue elements associated with them merging at the periphery with the alveolar septa, which appeared thickened. Neither in the lung nor in the pleura did they resemble " rheumatoid nodules." The arteries of the complexes showed changes of varying age and severity, the earliest consisting of an area of fibrinoid necrosis involving a part (Fig. 6 ) or the whole of the wall of a vessel, which was surrounded by a cuff of lymphocytes and plasma cells. The walls of the adjacent bronchioles showed infiltration by similar cells. Other vascular lesions consisted of marked swelling of the endothelium with oedema, accompanied by lymphocytes and plasma cell infiltration of all the coats (Fig. 7). In the older lesions there was thickening and fibrosis, both of the bronchioles and of the intima and adventitia of the small vessels; these were bound together to form the fibrous nodular complex described above. A simple fibrous nodule remained as the end-result in the oldest lesions of all (Fig. 8). Other lesions were seen, one of which was a nodule of cellular fibrous tissue infiltrated by lymphocytes and plasma cells, projecting like a polyp into the alveolar lumen (Fig. 9). Another was a nodule of osteoid tissue adherent to an alveolar wall (Fig. 10) resembling similar lesions occasionally seen in the lung in mitral stenosis. Fibrous thickening of the alveolar walls was seen in one area similar to that described by Ellman and Ball (Fig. 11), but there were no foci of fibrosing pneumonitis. Some alveoli showed emphysematous distension with broken alveolar septa terminating in club-like masses of collagen indistinguishable from the Masson bodies of the lung of mitral stenosis. Occasional bronchioles and alveoli contained a few polymorphs, apparently a terminal early bronchopneumonia.

Tracheobronchial lymph nodes were congested. anthracotic, and oedematous, and contained many plasma cells.

AdRENALS.-The adrenals showed thinning of the cortex, especially of the zona fasciculata.

No significant microscopic lesions were seen in the liver, kidney, spleen, heart, pituitary, brain, thyroid, pancreas, or bone marrow. 

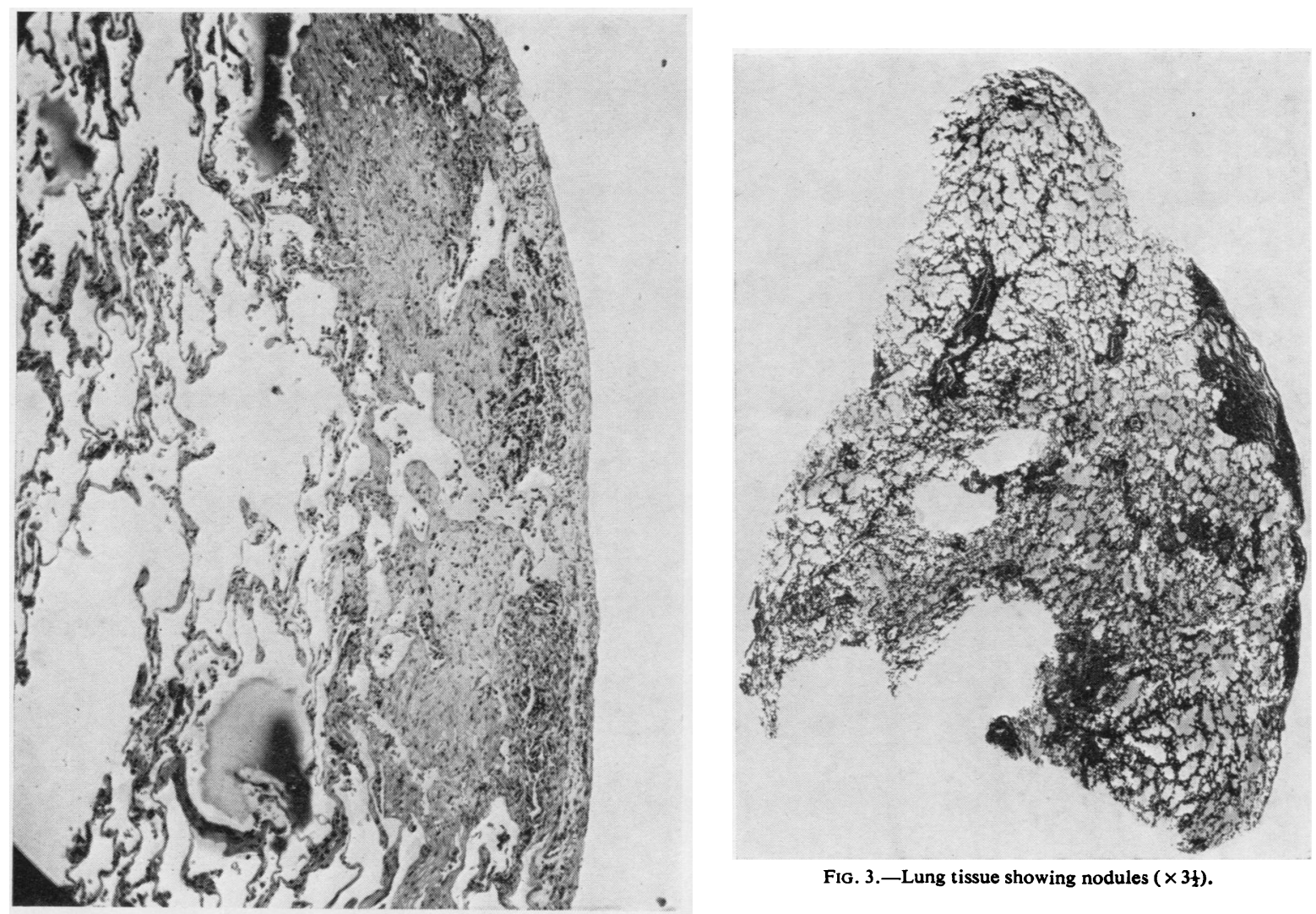

Fig.2.-Subpleural fibrous nodules $(\times 50)$.

FIG. 3.-Lung tissue showing nodules $\left(\times 3 \frac{1}{2}\right)$.

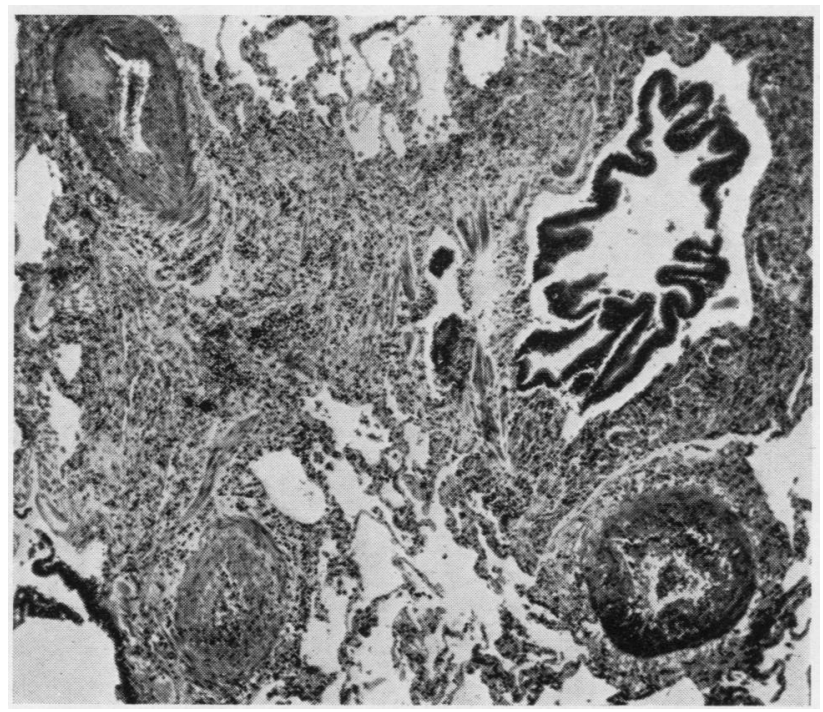

Fig. 4.-Nodular complex showing arteritis and bronchiolitis, active stage $(\times 50)$. 


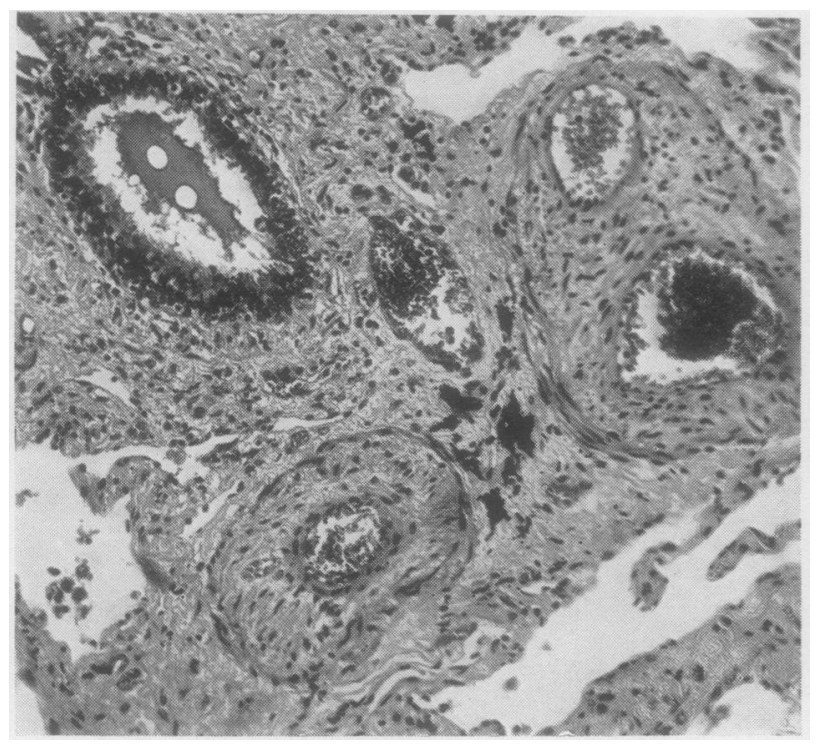

Fig. 5.-Nodular complex, healing stage $(\times 50)$.

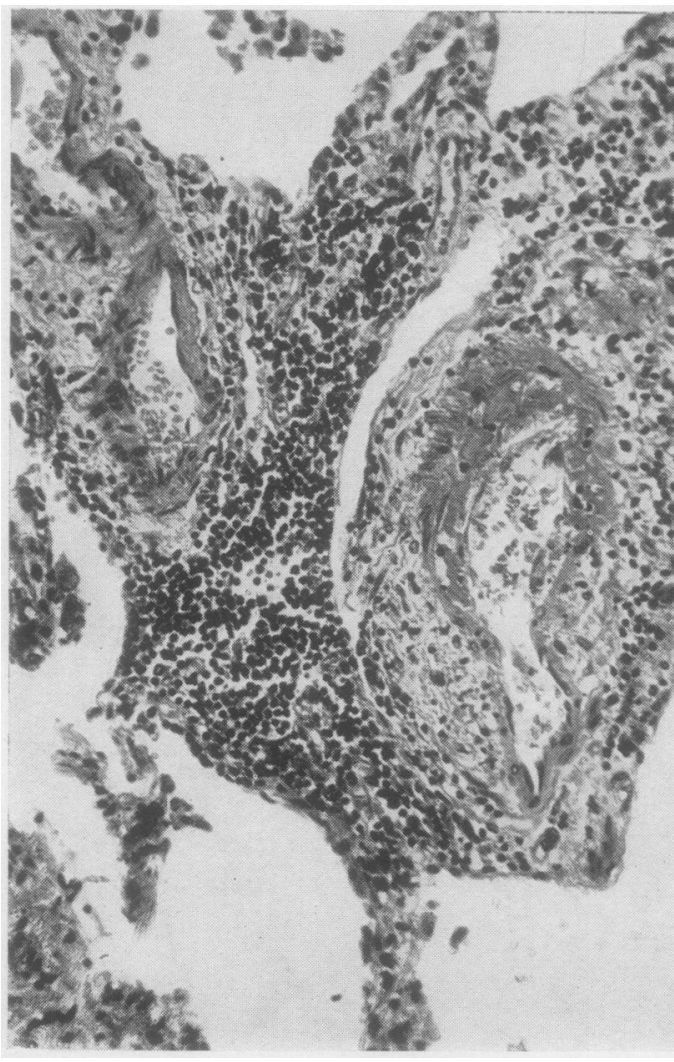

FIG. 6. -Fibrinoid necrosis of part of the wall of a vessel $(\times 180)$.

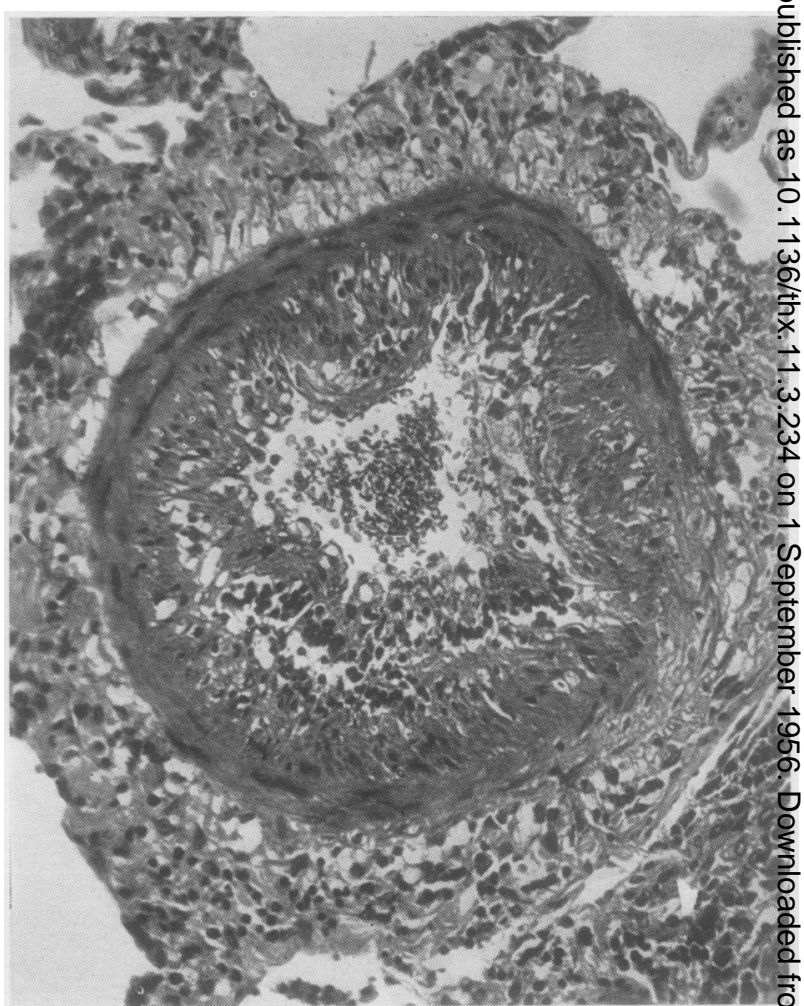

FIG. 7.-Small pulmonary artery showing fibrinoid necrosis and cellular infiltration $(\times 180)$

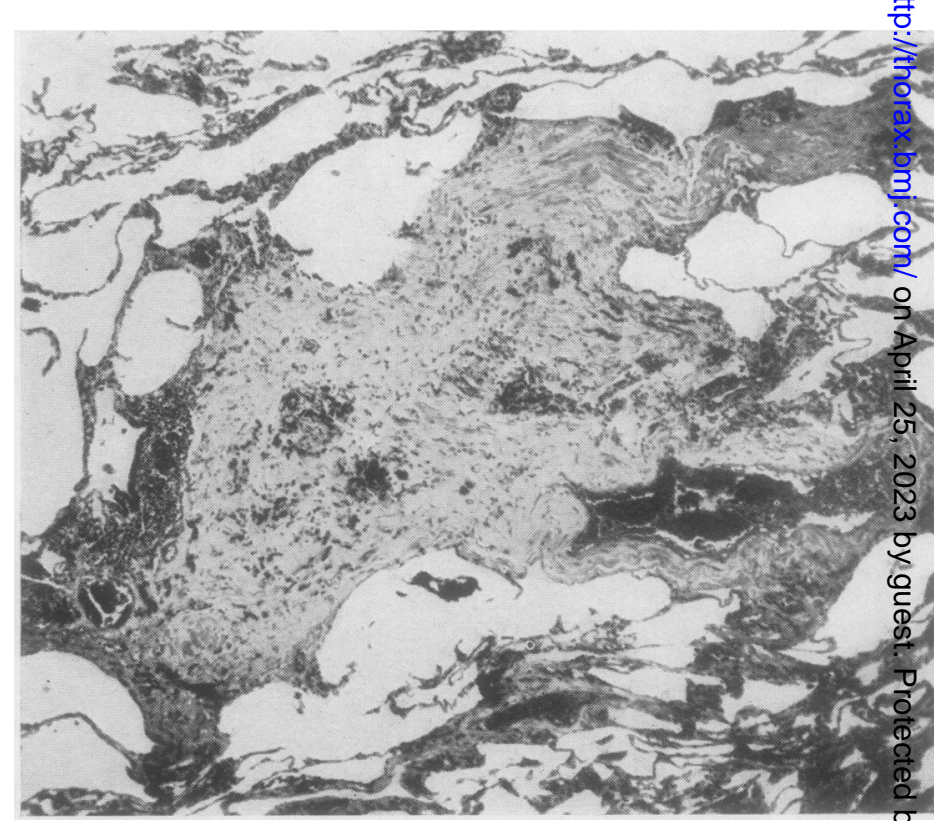

FIG. 8. - Nodular complex, healed stage $(\times 50)$. 


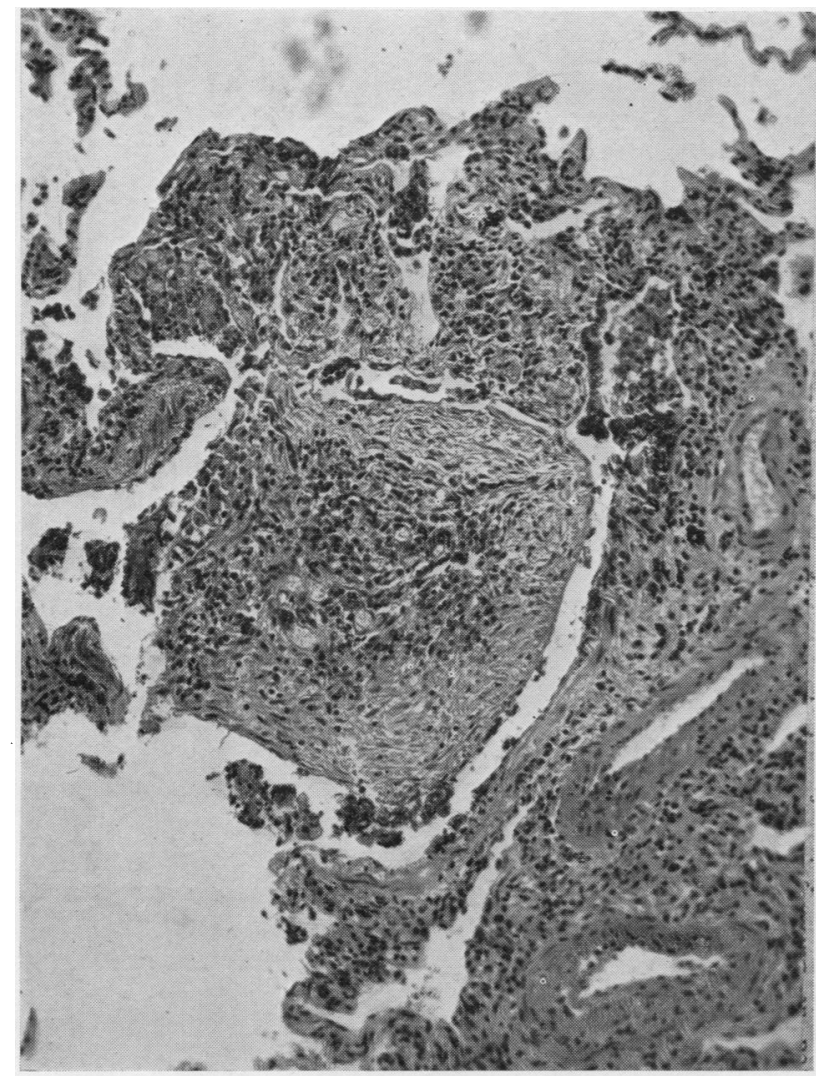

FIG. 9.-Polypoid nodule of fibrous tissue projecting into an alveolus ( $\times 110)$.

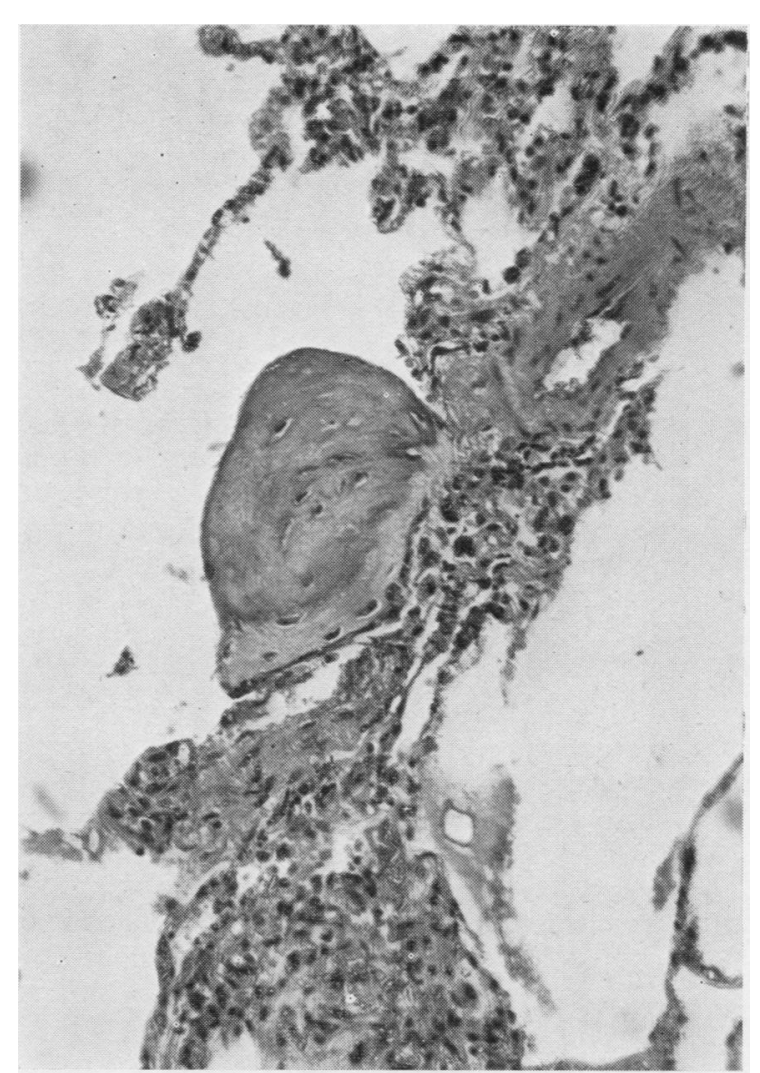

Fig. 10.-Nodule of osteoid tissue projecting into an alveolar lumen $(\times 110)$.

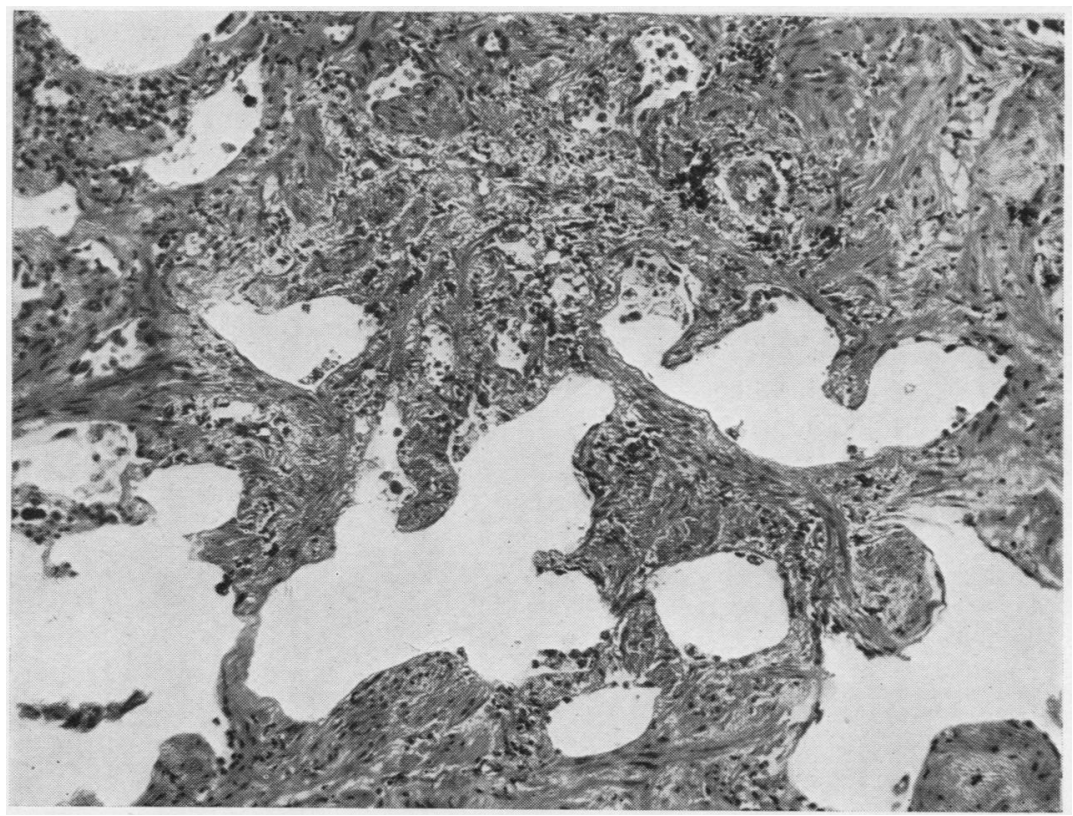

Fio. 11.-Lung showing thickening of alveolar walls $\times 130$ ). 
KNEE-JOINT.-The synovia showed proliferation of synovial lining cells with focal infiltration of lymphocytes and plasma cells in the stratum synoviale, typical of rheumatoid arthritis.

The stomach showed a large chronic peptic ulcer.

\section{Discussion}

This is the case of a middle-aged woman who developed clinically what appeared to be rheumatoid arthritis, preceded for two weeks by signs and symptoms of a severe lung disorder. It is possible that the chest complaint had been present for a year before the arthritis, but it had not been severe and had consisted only of a slight cough.

The differential diagnosis of the polyarthritis was carefully considered. The appearances of the joints and the general clinical picture were in every way compatible with a diagnosis of rheumatoid arthritis, but, in view of the unusual lung changes, some form of collagen disease, especially disseminated lupus erythematosus, had to be kept in mind. The absence of leucopenia, the failure to find L.E. cells, and the severity of the arthritis were thought to be strong evidence against lupus erythematosus. We therefore concluded that the diagnosis of rheumatoid arthritis, which would never have been questioned had not the lung lesions subsequently developed, was correct.

Cortisone and A.C.T.H. produced a characteristic improvement in the arthritis but had no effect on the lungs. Radiologically the lungs showed diffuse mottling and reticulation in all zones. This appearance may be caused by a number of pathological processes having in common the production of minute nodular lesions in the lung; for example, miliary tuberculosis, sarcoidosis, and haemosiderosis. In a sense, such a picture is not specific in that it is not exclusively diagnostic of one particular disease. It is, however, specific for lesions of a particular pattern and size, and the microscopic lesions found in this case would be expected to produce these radiological appearances.

The types of lesion found at necropsy are scattered foci of inflammation affecting both bronchioles and accompanying small arteries. This arteritis, which is so striking a feature microscopically, seems to be one of the basic elements of the lesions. To suggest arteritis as a significant lesion in the evolution of "rheumatoid lung" is not to invoke any new concept of the disease process, arteritis being a well-known, if rare, complication of rheumatoid arthritis in other organs of the body. In Christie's (1954) reports active arteritis is described in the lungs of three of his cases and variously in spleen, kidney, and heart. There was arteritis in the lung, heart, and kidney in the first of the cases of Ellman and Ball (1948), but none in the second. Although arteritis is a striking feature of the lesions in our case, it is not sufficient to explain the entire appearance of the nodules which in addition show subacute inflammation of the walls of the bronchioles and cellular infiltration of the surrounding septa. These changes probably indicate damage to the pulmonary connective tissue in these areas.

Recently Aronoff, Bywaters, and Fearnley (1955), in a survey of cases of rheumatoid arthritis, stated that they had never seen a case of "rheumatoid lung" and rightly emphasized the difficulty of assessing the significance of lung shadows in patients with this disease, pointing out that these may be due to entirely unassociated conditions. In our case, however, we think the nature of the lesions is such that no other disease process need be invoked.

\section{SUMMARY}

The case is described of an elderly woman with rheumatoid arthritis and clinical and radiological evidence of a severe pulmonary disorder. At necropsy scattered focal lesions were found in the lung, prominent amongst which was an active subacute inflammation of the arteries and bronchioles. It is suggested that there is a characteristic appearance occasionally found in the lungs of people with rheumatoid arthritis which may conveniently be described by the term "rheumatoid lung" and that arteritis, bronchiolitis, and damage to the pulmonary connective tissue are basic processes responsible for its production.

We are grateful to Professor G. J. Cunningham for his help and interest.

\section{REFERENCES}

Aronoff, A. Bywaters, E. G. L., and Fearnley, G. R. (1955). Brit. med $J ., 2,228$.

Christie, G. S. (1954). Aust. Ann. Med., 3, 49.

Ellman, P., and Ball, R. E. (1948). Brit. med. J., 2, 816.

Rubin, E. H. (1955). Amer. J. Med., 19, 569. 